\title{
Tobacco harm reduction: the devil is in the deployment
}

The concept of harm reduction in tobacco control is exciting interest among policy makers and industry. Gerard Hastings, Marisa de Andrade, and Crawford Moodie argue that it presents public health with some challenges

\author{
Gerard Hastings professor, Marisa de Andrade research fellow, Crawford Moodie senior research \\ fellow
}

Institute for Social Marketing, University of Stirling, Stirling FK9 4LA, UK

The idea of tobacco harm reduction-that smokers who cannot wean themselves off nicotine should be encouraged to adopt less harmful ways of consuming it-has much to recommend it. It avoids the trap of making the excellent (complete cessation) the enemy of the good (reduced harm) and provides a way forward where otherwise there is only a cruel impasse. It also provides a clear focus on disease and premature death-rather than tobacco addiction or corporate power-and this enemy, like so many medical problems before it, will be defeated with rigorous evidence, effective medicines, and skilled treatment.

In the United Kingdom the National Institute for Health and Clinical Excellence has just produced draft guidelines on harm reduction approaches to smoking and the Medicines and Healthcare Products Regulatory Agency is considering licensing electronic cigarettes. ${ }^{1}$ These moves are in response to the emergence of a range of nicotine containing products that seem suitable for temporary or indefinite use as partial or complete substitutes for tobacco. These include nicotine replacement therapy (patches, sprays, gums, lozenges, inhalators), licensed by the MHRA as pharmaceutical treatments for smoking, and unlicensed products such as topical gels and a burgeoning array of electronic cigarettes (e-cigarettes). This proliferation of nicotine containing products raises the classic public health question: what happens when a good idea at an experimental level is taken to scale? The answer is complicated by business interests: both the tobacco and pharmaceutical industries are keen to exploit harm reduction.

\section{What does harm reduction offer tobacco control?}

As noted by NICE, ${ }^{1}$ harm reduction may help smokers with no intention or ability to quit to gradually wean themselves off cigarettes. For people who have tried everything to quit but simply cannot manage without nicotine, the case for harm reduction seems self evident: immediate lives will be saved. However, a broader perspective suggests potential problems.

Firstly, the new nicotine containing products are not intuitively appealing; smokers will need to be persuaded of their benefits.
For public health there is a key benefit: it is easier to use them than to quit. But for most smokers quitting is the best option and should be presented as achievable and attractive. So rolling out harm reduction puts public health in the contradictory position of having to stress both the difficulties and attractions of quitting.

A related danger is that children will pick up on this apparent confusion. While previous generations were told simply that tobacco is bad; new ones would learn that nicotine is acceptable, just be careful how you access it. Moreover, promotion of harm reduction might reduce the perceived "cost" of uptake. Finally, the fact that e-cigarettes deliberately mimic conventional ones (even down to emitting fake smoke) may result in the inadvertent modelling of smoking (box 1).

More broadly, the media, which (at least in the UK) has become a reliable supporter of comprehensive control measures, might also struggle with this more complex position. Thus the benefits of harm reduction are not as obvious as they first seem. The two corporate players will further muddy the water.

\section{What is in it for the tobacco industry?}

It is nearly half a century since the tobacco industry recognised that it is "in the business of selling nicotine, an addictive drug.", Nevertheless, it has been notoriously shy about this reality, so much so that 30 years after the original admission it was prepared to perjure itself to the US Congress rather than even admit that nicotine is addictive-let alone that it would ever exploit the resulting human frailty. ${ }^{3}$ Harm reduction, however, introduces the possibility of public health formally recognising that selling recreational nicotine is an acceptable-even good-idea, provided you clean up the delivery mechanism.

The tobacco industry's marketing skills could help smooth the difficult transition from tobacco to e-cigarettes, but again there are concerns. Harm reduction is more profitable than abstinence but not than continued smoking. And even in an advanced tobacco control market like the UK, the tobacco industry stills gets over $99 \%$ of its profits from smoked tobacco. ${ }^{4}$ Given this 


\section{Box 1: Using harm reduction to promote smoking}

Brand stretching - Major smoked tobacco brands, including Marlboro (fig 1 $\downarrow$ ), Lucky Strike, and Peter Stuyvesant, have been attached to harm reduced snus products providing respectability by association just as Camel boots and Marlboro Classic clothing did a generation ago.

Evocative advertising —Non-tobacco harm reduction products are being promoted with evocative advertising (fig $2 \downarrow$ ). Addition of tobacco branding to packaging could make the distinction between their use and smoking harder to draw

Undermining smoke-free ordinances_-Smokeless products (whether tobacco based or not) are being promoted as "work friendly" or "when smoking isn't an option" and so are presenting an alternative to quitting in the face of smoke-free ordinances

Modelling-Electronic cigarettes are designed to mimic real ones, and this may reinforce the idea of smoking

asymmetry, the industry is inevitably using harm reduction to boost the much more profitable conventional products (box 1).

Hence the tobacco industry's involvement in harm reduction is mired in double standards. When British American Tobacco (BAT), for instance, calls for a broader approach "that accepts that many adults are going to continue to use tobacco and nicotine products," 5 the words are overshadowed by the fact that the majority of the company's marketing budget is focused on encouraging continued smoking. And when the company says that it has "a responsibility to pursue ways in which we might reduce the health risks of our products" the reflex response from public health has to be: "Stop marketing them so assiduously across the globe."

Even when the tobacco industry genuinely pursues the non-tobacco nicotine market, there are concerns. The profitability of the cigarette lies principally in the fact that most smokers stick with the habit (and the product) for decades. The tobacco companies will want to repeat this success with e-cigarettes: they will use their marketing muscle to ensure that consumers continue to use their products for as long as possible.

Tobacco companies are also using harm reduction in their stakeholder marketing ${ }^{6}$ - the efforts they put into building links with powerful subgroups in society. BAT's recent Sustainability Report, for example, emphasises how it is "preparing for the future" by "engaging with regulators, scientists and the public health community to develop the scientific and regulatory frameworks needed to deliver reduced-risk products." ${ }^{" 7}$ The fact that two years ago the company's head of public health and scientific affairs was invited by NICE to present to its Citizen's Council on harm reduction, shows it is succeeding. ${ }^{8}$ Such collaboration could easily undermine the World Health Organization's Framework Convention on Tobacco Control, which outlaws working with the tobacco industry.

\section{What is in it for the pharmaceutical industry?}

In 2009 the UK nicotine replacement therapy market was worth $£ 125 \mathrm{~m}$, and in 2011 the UK government spent $£ 66.4 \mathrm{~m}$ on subsidising these products. ${ }^{9}{ }^{10}$ Significant though these sums are, they represent only $1 \%$ of the value of the tobacco market, mainly because usage is measured in weeks, rather than the decades for tobacco. Just like the tobacco companies, then, the drug industry wants to extend the duration of use, which explains why it has been so active in the legitimisation of harm reduction (box 2).

Like tobacco companies, the pharmaceutical industry will use its marketing skills to keep people in the nicotine market. This task will be made easier by the NICE guidelines, which explain that licensed nicotine containing products, while intended for short term use, are considered suitable for use in the medium term-and even as lifelong substitutes for cigarettes. ${ }^{1}$

Harm reduction also offers the drug companies useful stakeholder marketing opportunities: it enables them to maintain and enhance relationships with the same scientists and policy makers that the tobacco industry is courting.

\section{Shared interests}

Thus both the tobacco and pharmaceutical industries have a vested interest in a legitimised market for nicotine and links between the two sectors can only increase. BAT's recent launch of a subsidiary called Nicoventures to focus on the "development and commercialisation of innovative regulatory approved nicotine products" ${ }^{14}$ is a harbinger of things to come.

Harm reduction also raises more fundamental questions about the role of public health. Specifically, we need to ask whether its job is to save or to empower. If it is to save, then getting people to stop smoking using whatever means possible becomes the priority - and leaving them dependent on nicotine is not a concern compared with the harm avoided. The second perspective, however, suggests a need to think not just about tobacco but diet, alcohol use, exercise, and the many other behaviours that affect health outcomes. Broader, health promoting perspectives are needed that focus on the areas that motivate people and "give them the confidence that they can change. ${ }^{15}$ From this standpoint, harm reduction's accommodation with ongoing nicotine dependence is much more problematic.

More widely still, a key concern with tobacco is that it ties people to an exploitative multinational industry; harm reduction merely changes the identity of this industry. Comparisons with coffee have been made in response to this, equating caffeine with nicotine. For the most part this parallel does not stand up to closer analysis (box 3), but the trades in coffee and tobacco do have one important commonality. Both markets provide numerous examples of producers being exploited and damaged by multinationals. ${ }^{16}$ Public health should be just as concerned about this form of harm as it is about that caused by chemical toxins.

The debate about harm reduction needs to encompass this broader level of analysis - to recognise that the framing we noted in the first paragraph that the enemy is disease and premature death not tobacco addiction or corporate power is, in the real world, simply naive. It ignores the politics of health and the multiple flaws in the system.

\section{Conclusion}

Harm reduction matters. There have to be alternatives for those who cannot quit. Furthermore, the commercial opportunities for both the tobacco and pharmaceutical industries mean it is here to stay. The question is how public health should respond. The issues are fraught, but five conclusions are clear:

- Collaboration with the tobacco industry is likely to backfire. The industry's overwhelming dependence on smoked tobacco sales means that, for the foreseeable future, harm reduction will be the servant of this much bigger unhealthy cause 


\section{Box 2: The pharmaceutical industry's role in driving forward harm reduction}

The process started by promoting the idea to the MHRA that nicotine replacement therapy (NRT) could be a stepping stone to quitting ${ }^{11}$ as well as a direct cessation aid. Next the concept of harm reduction was fostered when the manufacturer of the Nicorette inhalator formally requested an extended application for its product. The MHRA agreed the extension, saying:

"Nicorette Inhalator relieves and/or prevents craving and nicotine withdrawal symptoms associated with tobacco dependence. It is indicated to aid smokers wishing to quit or reduce prior to quitting, to assist smokers who are unwilling or unable to smoke, and as a safer alternative to smoking for smokers and those around them."12

The report went on to conclude: "In addition, the Working Group recommended a 'harm reduction' element was appropriate for the indications of all other currently authorised forms of NRT."

In February 2010 the MHRA recognised that "the extension of the indication for NRT to include harm reduction raises the question of the regulation of other unlicensed nicotine containing products on the market such as electronic cigarettes, which have not been assessed for safety, quality, and efficacy."13

An entirely new treatment had emerged for the problem of smoking.

\section{Box 3: Coffee and tobacco-key differences}

The coffee industry is argued to be another multinational exploiting our dependence on a drug (in this case caffeine) yet this raises few concerns; by extension a market in nicotine could become as innocent as our morning cuppa. However, there are three crucial differences:

- Caffeine consumption is not linked to any major health problems; while nicotine itself seems to be relatively harmless, its addictive properties mean that the most nicotine consumption is, and will continue to be for the foreseeable future, extremely unhealthy

- Caffeine consumption is not related to disadvantage; nicotine consumption is deeply regressive

- Caffeine is only a small part of the coffee story as the popularity of decaffeinated coffee attests; de-nicotined cigarettes have proved a much less attractive consumer proposition

- Collaboration with the pharmaceutical industry is also problematic because its priority will always be private profitability rather than public health. This will be manifested in a focus on prolonging use, which could mean indefinite use

- In the long term, the aim of both industries is to stimulate and grow the market in nicotine, and immense marketing effort will be used to further this strategy

- Harm reduction has the potential to deflect the strategic direction of tobacco control. Benefits need to be judged not just in the narrow sense of lives saved among users but by comparison with other tobacco control options and the contribution to a comprehensive strategy

- It is important to think beyond the UK. If the government continues to collaborate with the tobacco industry on harm reduction, this will confer a dangerous legitimacy that will be exploited in other countries with much less advanced tobacco control policies and undermine the Framework Convention on Tobacco Control.

Harm reduction is a potentially valuable tobacco control tool, but it needs to be taken forward with great care. Anything approaching public health backed population level implementation is likely to do more harm than good.

The MRHA is currently considering the licensing of e-cigarettes. ${ }^{1}$ Until this happens, their safety and efficacy remains unproved and they should not be recommended for cessation or harm reduction. If a licence is issued, marketing restrictions should be extremely tight to avoid counterproductive promotion. The controls implemented in New Zealand, where e-cigarettes cannot be used therapeutically, provide a good model (box 4). ${ }^{17}$ In addition, any tobacco brand sharing must be treated as a breach of the UK advertising ban. Robust research programmes should also be put in place to monitor the effect of harm reduction so that the regulatory regime can be adjusted as needed (box 5).

Contributors and sources: GH has conducted research, advised national and international public bodies, and written articles and books on the impact of business on society. GH conceived of and drafted the original paper and is the guarantor; MDA edited and added to this draft, particularly with respect to the pharmaceutical dimension; $\mathrm{CM}$ commented on drafts and added material.

Competing interests: The authors have completed the ICMJE unified disclosure form at www.icmje.org/coi_disclosure.pdf (available on request from the corresponding author) and declare no support from any organisation for the submitted work; no financial relationships with any organisation that might have an interest in the submitted work in the previous three years; GH is the director of the CRUK Centre for Tobacco Control Research; a principal investigator on the International Tobacco Control Study, the UK Centre for Tobacco Control Studies, and the MRC funded APISE study; and a member of the Public Health Research Consortium.

Provenance and peer review: Not commissioned; externally peer reviewed.

1 National Institute for Health and Clinical Excellence. Tobacco: harm reduction approaches to smoking, 2012. www.nice.org.uk/nicemedia/live/13018/61198/61198.pdf.

2 Yeaman A. Implications of Battelle Hippo I \& II and the Griffith Filter. Brown and Williamson Tobacco Company, July 17, 1963. Bates No 1802.05. http://legacy.library.ucsf.edu/tid/ xrc72d00.

3 Tobacco CEO's statement to Congress 1994 news clip "Nicotine is not addictive." http:// senate.ucsf.edu/tobacco/executives1994congress.html.

4 Euromonitor. Tobacco-United Kingdom. Country market insight. Euromonitor International, November 2009.

5 British American Tobacco. Sustainability report 2011: harm reduction. www.bat.com/ groupfs/sites/BAT_8NXDKN.nsf/vwPagesWebLive/DO8QDDPM?opendocument\&SKN=1.

6 Davis RM, Gilpin EA, Loken B, Viswanath $\mathrm{K}$, Wakefield MA. The role of the media in promoting and reducing tobacco use. NCI Tobacco Control Monograph Series No 19. $\mathrm{NIH}$, June 2009.

7 British American Tobacco. Sustainability report 2011. www.bat.com/groupfs/sites/BAT 8NXDKN.nst/vwPagesWebLive/C125795300362522C125785E0041A945/\$FILE/Full_ sustainability_report_2011.pdf?openelement.

8 O'Reilly D. Tobacco harm reduction-a view from a tobacco company. NICE Citizens Council, 15-16 October 2009.

9 Euromonitor. NRT smoking cessation aids_-United Kingdom. London: Euromonito International, 2009.

10 NHS Information Centre. Prescription cost analysis England 2011. Health and Social Care Information Centre, 2012.

11 Committee on Safety of Medicines. Report of the working group on nicotine replacement therapy (MHRA). www.mhra.gov.uk/home/groups/pl-a/documents/websiteresources/ con2023239.pdf.

12 MHRA. Public assessment report. The use of nicotine replacement therapy to reduce harm in smokers. 2009:5.

13 MHRA. Drug safety update. Nicotine replacement therapy and harm reduction. www.mhra. gov.uk/Safetyinformation/DrugSafetyUpdate/CON087732.

14 Nicoventures: What is Nicoventures? www.nicoventures.co.uk/what-is-nicoventures. 2012.

15 Buck D, Frosini F. Clustering of unhealthy behaviours over time: implications for policy and practice. King's Fund, 2012.

16 Oxfam. Policy and practice. Mugged: poverty in your coffee cup. http://policy-practice. oxfam.org.uk/publications/mugged-poverty-in-our-coffee-cup-112445.

17 Medsafe (Regulatory Information). Guidelines and codes: categorisation of electronic cigarettes. www.medsafe.govt.nz/regulatory/Guideline/ElectronicCigarettes.asp.

Accepted: 30 November 2012 
Box 4: Restrictions on promotion of e-cigarettes in New Zealand ${ }^{17}$

E-cigarettes cannot be promoted:

- As gadgets

- As social props

- As dual purpose products along with cigarettes

- As flavoursome products for enjoyment

- In places where smoking is prohibited

- As an alternative to smoking

- As a cooler and safer way to smoke

\section{Box 5: Key research questions}

- How many smokers opt for nicotine long term, either through choice or as a consequence of multiple failed quit attempts?

- What harm reduction approaches are smokers currently using, are these changing, and what effect do they have on different subpopulations (eg, young people)?

- What is the effectiveness of harm reduction on smoking rates at a population level?

- Are there unintended consequences of harm reduction strategies?

- What are the health benefits of reduced consumption with the help of licensed nicotine-containing products rather than unaided, with self help materials, or using different behavioural strategies?

- How will the tobacco and drug industries use harm reduction in their business strategies?

\section{Related links}

\section{bmj.com}

- Feature: Electronic cigarettes: medical device or consumer product? (2012;345:e6417)

(c) BMJ Publishing Group Ltd 2012 


\section{Figures}

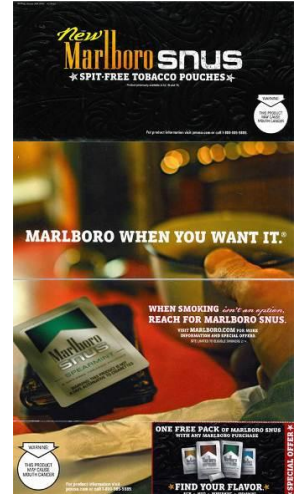

Fig 1 Marlboro advert for snus

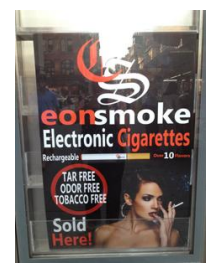

Fig 2 Recent advert for e-cigarettes from New York 